\title{
Alquimia y atomismo en el Quijote
}

\author{
Carlos García-Verdugo Caso*
}

\section{INTRODUCCIÓN}

Un escritor recoge las ideas de su tiempo y las utiliza para un fin artístico. Resulta interesante extraer las ideas y conceptos que una persona de una determinada época posee acerca de campos tan amplios como la ciencia. Es una forma de entender hasta qué punto han penetrado en la sociedad los acontecimientos científicos que ayer, como hoy, suelen pertenecer a un ámbito a menudo minoritario. Es una tentación intentar encontrar ideas subyacentes en el texto que pudieran ir a contracorriente en la época del autor; esto, sin duda, resulta llamativo, pero tiene el peligro de convertirse en pura elucubración del estudioso y no en reflejo de la realidad del tiempo del escritor. Debemos asumir, en este sentido, que la novela que nos ocupa ${ }^{1}$ no es sino «una invectiva contra los libros de caballerías» (I, Prólogo, 18).

En realidad, de acuerdo con nuestro famoso hidalgo, la ciencia de las ciencias es la de la caballería andante. En el diálogo con don Lorenzo, nuestro famoso caballero aclara que esta ciencia «es tan buena como la de la poesía, y aun dos deditos más» (II, 18, 844) ya que «encierra en sí todas o las más ciencias del mundo» (ibíd.). Dentro de estas ciencias se encuentra la de «ser médico, y principalmente herbolario, para conocer en mitad de los despoblados y desiertos las yerbas que tienen virtud de sanar las heridas, que no ha de andar

* UNED, Centro Asociado de Cádiz.

1. M. De Cervantes, Don Quijote de la Mancha. Edición del Instituto Cervantes, 1605-2005, Barcelona, Galaxia Gutenberg-Círculo de Lectores, 2004. Todas las citas del presente trabajo se han extraído de la citada edición. 
el caballero andante a cada triquete buscando quien se las cure; ha de ser astrólogo, para conocer por las estrellas cuántas horas son pasadas de la noche y en qué parte y en qué clima del mundo se halla; ha de saber las matemáticas, porque a cada paso se le ofrecerá tener necesidad dellas» (II, 18, 845). Observemos en este extracto cómo se mezclan en esta ciencia de la caballería andante - que no es «ciencia mocosa»_, la medicina, la alquimia, la astrología, la astronomía o la cosmografía. También se deben tener en cuenta otras ciencias como saber nadar, herrar un caballo o aderezar la silla y el freno. Pero estas no serán objeto de estudio en el presente trabajo.

En la inmortal obra de Cervantes podemos rastrear ecos de lo que una persona culta entiende por ciencia en el siglo XVI y hasta la época de su publicación (1605, la primera parte, y 1615, la segunda). En el Quijote nos encontramos con una visión todavía arcaica del concepto de ciencia basada en los principios aristotélicos sobre la materia y la forma, así como en el sentido teleológico de todo cambio. El universo está sometido al marco ptolemaico, y la medicina sigue aún los dictados galenistas ${ }^{2}$.

En el mismo sentido, se nota una influencia astrológica de los planetas sobre el hombre y la naturaleza, o un paralelismo entre el macrocosmos y el microcosmos aún no superado. En realidad, nos veremos abocados a ejemplificar y a contextualizar los reflejos de lo que Berthelot llamaría «ciencias intermedias ${ }^{3}$, como la astrología o la alquimia; enfocaremos el estudio profundizando en esta última, tanto en sus representaciones esotéricas — que también existen en la obra - como en los aspectos exotéricos, cuyos brillos en el laboratorio comenzaban a conducir, por negación de las orientaciones quiméricas y charlatanescas, al trabajo químico. A este camino empezado en los laboratorios se unirán, andando el tiempo, las ideas atomistas. También es posible encontrar, para gozo de los mecanicistas —o quizá no tanto-, ejemplos de atomismo; de ellos daremos cuenta pormenorizadamente.

\section{Alquimia, HERMETISMO Y ASTROLOGÍA}

La alquimia se sustentó desde sus principios, tanto en un conjunto de técnicas de tipo artesanal, como en especulaciones filosóficas y místicas de naturaleza abstracta $^{4}$. En la Alejandría posterior a la muerte de Alejandro el Grande el pensamiento griego tomó íntimo contacto con el espíritu práctico de los egipcios; a esta mezcla se incorporó, también, el misticismo oriental. Este origen híbrido y complejo marcó a lo que los griegos llamaron arte sagrado, y los árabes alquimia, con un carácter mestizo entre lo racional y lo irracional del

2. C. García-Verdugo Caso, El concepto de Ciencia en el Quijote, El Puerto de Santa María, Academia de Bellas Artes Santa Cecilia, 2004, pp. 37 y ss.

3. M. Berthelot, Les origines de l'alchimie, Paris, George Steinheil, 1885. Tomado de Los origenes de la alquimia, trad. José Valero Bernabéu, Barcelona, MRA, 2001, p. 13.

4. W. H. Brock, Historia de la química, Madrid, Alianza, 1998, pp. 23-48. 
que no se liberaría durante toda su dilatada historia. La confluencia de estas naturalezas — filosófica, tecnológica y mística — conducirá, como es sabido, a conclusiones insólitas y extraordinarias.

El lenguaje de los alquimistas alejandrinos y medievales es casi siempre esotérico. Se apropia de símbolos mágicos y místicos para cercar sus recetas sobre materiales, métodos y aparatos dentro de una oscuridad intencionada que evite la revelación a los no iniciados. De hecho, dichas recetas venían a expresar un proceso de perfección cósmico y humano al que solo unos pocos podrían acceder.

Los conceptos alquímicos derivan de dos fuentes: el hermetismo y el corpus filosófico resultante de la síntesis del platonismo y el aristotelismo ${ }^{5}$.

Del hermetismo, la alquimia recibió conceptos esenciales, como la idea de unidad y vida cósmica, la jerarquización cósmica, la caída cósmica que había escindido el mundo en opuestos, generándose una dualidad — entendida como un desgarro - que habría arrastrado también al hombre. Excepto al Caballero del Bosque, que en su soneto nos llega a decir:

A prueba de contrarios estoy hecho, de blanda cera y de diamante duro, ... (II, 12, 789).

Gracias a la conjunción de los opuestos realizada por el alquimista se restituía la unidad original. El universo, abarcable e interconectado, afecta al ser humano; el macrocosmos influye en el microcosmos. Se deja, así, ver la influencia de otro «arte divino»: la astrología; aunque el ser humano —el alquimista - también puede llegar a afectar al gran mundo. En este sentido, los siete metales conocidos por los alquimistas son engendrados por la tierra debido a las emanaciones provenientes de los siete cuerpos celestes. Estas emanaciones están presentes en la obra cuando, en la historia de Cardenio, llora este la traición de don Fernando y su desventura amorosa con su amada Luscinda:

Mas ¿de qué me quejo, desventurado de mí, pues es cosa cierta que cuando traen las desgracias la corriente de las estrellas, como vienen de alto abajo, despeñándose con furor y con violencia, no hay en la tierra que las detenga, ni industria humana que prevenirlas pueda? (I, 27, 335).

Sobre la idea de vida cósmica no se encuentran claros ejemplos en el texto; una especie de hilozoísmo de esta naturaleza estaría en abierta contradicción con los principios religiosos imperantes en la época. Sin embargo, podemos encontrar algún llamativo ejemplo de cómo el macrocosmos influye en el microcosmos; el universo, en el hombre. Así, nuestro famoso caballero nació

5. F. J. Olivares del Valle, Noción de átomo y su historia, Cáceres, Universidad de Extremadura. Servicio de Publicaciones, 1998, p. 81. 
debajo de la influencia del planeta Marte (II, 6, 737),

aunque a veces también se canse de su ajetreada vida; así, podemos leer cómo don Quijote y Sancho deciden volver a la aldea, después del encuentro con los disciplinantes:

—Bien dices, Sancho — respondió don Quijote—, y será gran prudencia dejar pasar el mal influjo de las estrellas que agora corre (I, 52, 644).

En la segunda parte, Sansón Carrasco, socarrón famoso, se dirige a la señora ama desengañándola de sus infructuosos esfuerzos para evitar la salida de nuestro hidalgo

... que yo sé que es determinación precisa de las esferas que el señor don Quijote vuelva a ejecutar sus altos y nuevos pensamientos... (II, 7, 744).

El sentido de las esferas es el clásico de los cielos que arrastran a los planetas en su giro circular, perfecto, perpetuo e imperturbable, pero que también tienen su influencia astrológica en el hombre. En este sentido, cabe recordar que la «astronomía práctica» o astrología tenía un doble aspecto: el astrológico predictivo, que pretendía el conocimiento de las influencias de los astros con la intención de ayudar a los hombres a decidir sobre aspectos de su vida sin temor a errores, y la astrología determinista o judiciaria, que mantenía que la posición de los planetas imponía el destino de los hombres. La primera corriente estaba plenamente aceptada en la época de nuestro hidalgo. Sin embargo, la segunda era rechazada por negar el libre albedrío de los hombres. Observemos que don Quijote, aunque admite la influencia del macrocosmos, debe y puede tomar sus propias decisiones, como la de volver a la aldea o la de iniciar una nueva salida. Ello contrasta con la visión determinista de Cardenio, quien podría tener problemas con el poder eclesiástico; de hecho, la bula de enero de 1586 de Sixto V prohibía expresamente ejercer el arte de la astrología judiciaria, hacer encantamientos, adivinaciones y hechicerías, y leer y tener libros sobre estos menesteres. De cualquier manera, debemos entender las palabras de Cardenio como las propias de cualquier enamorado al límite de la desesperación última. Además, el rechazo a estas prácticas era por lo general, más formal que real ${ }^{6}$. (dir.), Barcelona, Crítica, 2005, p. 29. 


\section{Alquimia Y PLATONISMO}

La alquimia adoptó del platonismo la teoría de las ideas y arquetipos, la existencia de un mundo de esencias universales y de formas puras. La caída cósmica original había provocado una degradación por la que las ideas se convirtieron en cosas materiales que conservaban la reminiscencia de las formas arquetípicas.

El alquimista podía colaborar con la naturaleza y ayudarla a modificar las cualidades de la materia ${ }^{7}$. Estas modificaciones ocurrirían sin necesidad de que el hombre interviniera en el proceso cósmico de perfeccionamiento de la materia; sin embargo, el alquimista sí podía acelerar ese proceso. La alquimia es un intento de elevar las cosas al nivel perfecto e incorruptible de las ideas puras $^{8}$. En el momento en que esto se consigue se ha alcanzado el oro alquímico, la quintaesencia.

Observemos cómo cobran pleno sentido, a la luz de este concepto de quintaesencia, las palabras que el cura dirige a don Quijote cuando hace por encontrarse con este en el episodio de la princesa Micomicona:

- Para bien sea hallado el espejo de la caballería, el mi buen compatrioto don Quijote de la Mancha, la flor y la nata de la gentileza, el amparo y remedio de los menesterosos, la quintaesencia de los caballeros andantes (I, 29, 373).

El de la Triste Figura es la idea perfecta de la que el resto de los caballeros andantes solo son meras imitaciones.

\section{ALQUimia Y ARISTOTELISMO}

Como ya comentamos, la vitalidad del aristotelismo renacentista no deja lugar a dudas en nuestra famosa obra. De acuerdo con las ideas aristotélicas todo está conformado por una materia última que «no cabe decir que es algo determinado, ni que es de cierta cantidad $»^{9}$, que es por su naturaleza incognoscible ${ }^{10}$ y que no tiene existencia sino por adopción de diferentes formas. Las asociaciones materia-forma más primarias dan lugar a los cuatro elementos: el fuego, el aire, el agua y la tierra. Cualquier otro cuerpo está formado por combinación de los elementos anteriores.

Los cuatro elementos se pueden intuir en las siguientes palabras del narrador, cuando se describe lo que sucedió en Barcelona el día en que se celebraba la batalla naval:

7. M. Eliade, Herreros y alquimistas, Madrid, Alianza, 1986, p. 10.

8. F. J. Olivares del Valle, op. cit., p. 82.

9. Aristóteles, Metafisica, Madrid, Gredos, 2000, p. 273.

10. W. K. C. Guthrie, Historia de la filosofía griega, Madrid, Gredos, 1993, vol. VI, p. 223. 
El mar alegre, la tierra jocunda, el aire claro, sólo tal vez turbio del humo de la artillería, parece que iba infundiendo y engendrando gusto súbito en todas las gentes (II, 61, 1235).

Cada uno de estos elementos posee dos cualidades fundamentales: una determinante y otra secundaria. De esta forma, el fuego posee una cualidad determinante, que es el calor y otra cualidad secundaria, que es la sequedad. El aire es húmedo y caliente, el agua es fría y húmeda; la tierra es, por fin, seca y fría. En todos los casos se ha expuesto la cualidad principal en primer lugar. Un hecho esencial, y muy utilizado en la alquimia, es que se considera que cualquier elemento puede convertirse en otro diferente, sin más que alterar la propiedad secundaria. Así, el fuego puede perder sequedad y tomar humedad, transformándose en aire, este puede perder calor y adquirir frío, con lo que se convertirá en agua; y así con el resto de los elementos.

En la aventura de la piara de cerdos, pide Sancho a don Quijote que le deje seguir durmiendo y que no le apriete en lo de azotarle; Sancho, además, replica: «bien haya el que inventó el sueño, capa que cubre todos los humanos pensamientos, manjar que quita el hambre, agua que ahuyenta la sed, fuego que calienta el frío, frío que templa el ardor y, finalmente, moneda general con que todas las cosas se compran, balanza y peso que iguala al pastor con el rey y al simple con el discreto» (II, 68, 1289). Juega el autor con los elementos y sus cualidades, recordándonos la existencia de opuestos ya referida en el hermetismo.

Recordemos que este esquema tiene su paralelismo en la teoría de los humores que Galeno convirtió en canónica ${ }^{11}$ : sangre (caliente y húmeda), pituitaria o flema (fría y húmeda), bilis amarilla (caliente y seca) y bilis negra (fría y seca). Dichas ideas seguían plenamente vigentes aún en la época de nuestros famosos personajes.

Escuchemos cómo refiere Cardenio a Sancho, al cura, al barbero y al propio don Quijote su desventura amorosa en el crítico momento en el que, escondido, observa a su amada Luscinda desmayándose en su desposorio con don Fernando:

quedé falto de consejo, desamparado, a mi parecer, de todo el cielo, hecho enemigo de la tierra que me sustentaba, negándome el aire aliento para mis suspiros, y el agua humor para mis ojos; sólo el fuego se acrecentó, de manera, que todo ardía de rabia y de celos (I, 27, 342).

Pero los alquimistas superpusieron la idea de que existían dos principios que determinaban la forma exterior de la materia prima ${ }^{12}$ : el principio del azufre y el principio del mercurio. Así, todos los metales poseen el espíritu del azufre y el alma del mercurio; a esto se debe añadir un cuerpo, que es el princi-

11. J. M. LóPez PIÑERo, «La medicina en la antigüedad», Cuadernos Historia 16, n. ${ }^{\circ}$ 10, Madrid, Historia 16, 1995, p. 12.

12. F. J. Olivares del Valle, op. cit., p. 86. 
pio de la sal, que es entendido como aquello en lo que se cristaliza o en lo que se da forma. El azufre está vinculado con el fuego, el oro y el Sol; por su parte, el mercurio está entroncado con el agua, la plata y la Luna. El Sol y su secuencia simbólica oro-azufre aparece siempre como masculino, y la secuencia Luna-plata-mercurio se revela como lo femenino. De la unión de ambos principios debía surgir la quintaesencia; por ello la piedra filosofal emerge muy gráficamente como hermafrodita.

Entre los sucesos que acaecieron a nuestro caballero cuando salió de la venta tiene lugar la aventura de los mercaderes. Don Quijote exige con ademán arrogante a los mercaderes que se detengan y que confiesen que no hay doncella más hermosa en el mundo todo como la Emperatriz de la Mancha, la sin par Dulcinea del Toboso. Uno de los mercaderes, sin duda el más burlón del grupo, pide a nuestro hidalgo que se la muestre a los presentes para poder confesar la verdad que se les pide. Don Quijote exige una declaración sin miramientos, ante lo cual el sagaz mercader replica:

... y aun creo que estamos ya tan de su parte, que, aunque su retrato nos muestre que es tuerta de un ojo y que del otro le mana bermellón y piedra azufre, con todo eso, por complacer a vuestra merced, diremos en su favor lo que quiere (I, 4, 74).

Si analizamos estas palabras, observamos que el bermellón es y era en la época la principal fuente de mercurio. Por tanto, el mercader proclama que, aunque la sin par Dulcinea destile la esencia de lo femenino y aun de lo masculino, lo que sería propio de un hermafrodita, están dispuestos a complacer a nuestro caballero de la Mancha. El insulto era sutil, pero implacable, por lo que no es de extrañar la respuesta de don Quijote:

—No le mana, canalla infame — respondió don Quijote encendido en cólera-, no le mana, digo, eso que decís, sino ámbar y algalia entre algodones... (I, 4, 75).

\section{Alquimia e INFLUENCIA ÁRABE}

Desde la conquista de Alejandría, la alquimia helenística fue sistematizada en gran parte por los árabes. Convenientemente modificada, sería introducida posteriormente en Europa a través de la Península y del sur de Italia. La figura de Jabir ibn Hayyan (siglo VIII), latinizado Geber, aparece de forma destacada entre los alquimistas de tradición árabe. Una de las aportaciones más interesantes de Jabir a la alquimia de su tiempo fue la que se conoce como «teoría de la balanza ${ }^{13}$, que no fue sino una aplicación sistemática de la teoría de los 
cuatro elementos a la posibilidad de la transmutación. Así como el médico cura una enfermedad con medicamentos de la cualidad contraria, el alquimista se presenta como un médico de los metales, de modo que podrá curar a los metales impuros mediante el mismo sistema. De acuerdo con la filosofía aristotélica, todos los cuerpos están formados por los cuatro elementos; lo que diferencia a unos de otros es la proporción que se tiene de los mismos. De esta forma, entre el plomo y el oro solo hay diferencias de proporción entre los distintos elementos. La puerta de la transmutación queda así abierta. El alquimista tan solo debe variar adecuadamente las proporciones de estos elementos para convertir el plomo en oro.

Jabir plantea la posibilidad de realizar la transmutación mediante la participación del elixir filosofal, el cual, al ser añadido a un metal imperfecto le suministraría las proporciones que necesita para transformarse en oro, por la adquisición de sus propiedades.

Son, así, los árabes los que atribuyen virtudes terapéuticas a la piedra filosofal. Es esta, por una parte, una tintura para la transmutación, una medicina para los metales; pero, por otra, es un elixir para la inmortalidad, una medicina para el ser humano.

La transmutación es utilizada en la obra en el episodio del yelmo de Mambrino. Da don Quijote explicaciones sobre lo que Sancho ve como bacía de barbero:

... debió de venir a manos de quien no supo conocer ni estimar su valor y, sin saber lo que hacía, viéndola de oro purísimo, debió de fundir la mitad para aprovecharse del precio, y de la otra mitad hizo esta que parece bacía de barbero, como tú dices. Pero sea lo que fuere, que para mí que la conozco no hace al caso su trasmutación, que yo la aderezaré en el primer lugar donde haya herrero... (I, 21, 246-247).

Como elixir para la inmortalidad aparece en el episodio en el que don Quijote, herido en el duelo con el vizcaíno, habla a Sancho de

un bálsamo [...] de quien tengo la receta en la memoria, con el cual no hay que tener temor a la muerte, ni hay pensar morir de ferida alguna (I, 10, 125).

Sancho, claro está, no sabe leer ni escribir, pero es de un natural despierto del que es difícil encontrar parangón, por lo que responde:

Si eso hay [...] yo renuncio desde aquí el gobierno de la prometida ínsula, y no quiero otra cosa en pago de mis muchos y buenos servicios sino que vuestra merced me dé la receta de ese estremado licor... (I, 10, 126).

De nuevo se destacan las propiedades terapéuticas del bálsamo en el episodio de la venta que don Quijote pensó que era castillo. Nuestro hidalgo, después de comprobar que también Sancho ha sido aporreado, dice: 
—No tengas pena, amigo [...], que yo haré agora el bálsamo precioso, con que sanaremos en un abrir y cerrar de ojos (I, 17, 194).

\section{Alquimia COMO EXPERIENCIA RELIGIOSA}

De acuerdo con el hermetismo, la caída cósmica original que había escindido el mundo en opuestos había arrastrado al hombre. El alquimista intenta una especie de redención propia a través de la materia. La correspondencia con la simbología cristiana explica que se estableciese una analogía entre la piedra filosofal y Jesucristo ${ }^{14}$, llegándose a representar la obra alquímica en forma de misa y estableciéndose un paralelismo explícito entre la transmutación alquímica y la transformación eucarística ${ }^{15}$. La experiencia alquímica es equivalente, así, a una experiencia religiosa. La naturaleza puede ser vista y reconocida partiendo de Dios y Dios visto y reconocido en la naturaleza. Desde este punto de vista místico y esotérico, la piedra filosofal se identifica con el conocimiento de Dios.

En el episodio de la venta comentado anteriormente se puede leer cómo don Quijote

tomó sus simples, de los cuales hizo un compuesto, mezclándolos todos y cociéndolos un buen espacio, hasta que le pareció que estaban en su punto. [...] y luego dijo sobre la alcuza más de ochenta paternostres y otras tantas avemarías, salves y credos, y a cada palabra acompañaba una cruz a modo de bendición (I, 17, 196).

Observemos cómo se recurre a la ayuda divina para alcanzar la transmutación de los simples - romero, aceite, sal y vino - en un bálsamo de propiedades terapéuticas de tipo alquímico.

\section{Alquimia Y BOTICA}

A lo largo de la obra que nos ocupa podemos encontrarnos con una gran cantidad de términos boticarios ${ }^{16}$. Sin embargo, la ausencia real de novedades terapéuticas, exceptuando la incorporación de especies curativas vegetales del Nuevo Continente, y la visión contrarreformista del sufrimiento provocaban una actitud resignada hacia el dolor. Dado que la medicina y la hechicería se

14. Ibíd., p. 82

15. B. OBRIST, «Visualization in Medieval Alchemy», HYLE-International Journal for Philosophy of Chemistry, 9, 2003, 2, pp. 131-170.

16. Á. Del Valle Nieto, «Botica y farmacia en el Quijote», Anales de la Real Academia Nacional de Farmacia, 69, 2002, pp. 23-67. 
encontraban aún muy próximas ${ }^{17}$, podemos encontrarnos con situaciones y creencias curiosas para el hombre actual; un ejemplo se tiene en la utilización de aguas medicinales de virtudes milagrosas propias de los llamados «libros de secretos»». Tales libros proliferaron durante la segunda mitad del siglo XVI y contenían cientos de recetas que permitían solucionar cualquier problema de la vida cotidiana. Existían tres tipos de estos libros: medicinales, domésticos y técnicos. En estos últimos aparecen detalladas descripciones de procesos alquímicos y metalúrgicos ${ }^{18}$.

El ventero recomienda a don Quijote llevar una arqueta llena de ungüentos, como el resto de los caballeros andantes, pues no siempre había quien los curase

... si ya no era que tenían algún sabio encantador por amigo, que luego los socorría, trayendo por el aire en alguna nube alguna doncella o enano con alguna redoma de agua de tal virtud, que en gustando alguna gota della luego al punto quedaban sanos de sus llagas y heridas, como si mal alguno hubiesen tenido (I, 3, 61).

El agua de virtud era una infusión de plantas con una supuesta acción curativa o mágica capaz de rejuvenecer el rostro, cambiar el color del cabello o proporcionar la inmortalidad.

Durante los siglos XVI y XVII surge lentamente la idea de que la química trata con clases naturales de sustancias simples que pueden combinarse para dar lugar a sustancias compuestas con propiedades nuevas ${ }^{19}$. Ya hemos visto como don Quijote tomó sus simples para conseguir el bálsamo de Fierabrás, o del feo Blas, como lo llamaría Sancho en alguna ocasión (I, 15, 175). Aun con el peligro de caer en un anacronismo, si acudimos al Diccionario de Autoridades de $1739^{20}$, podemos leer que el término simple se aplica a cualquier cosa que no tiene composición alguna y, en otra de sus acepciones, comprobamos que un simple es aquel con el que llaman los botanistas y boticarios a las plantas, hierbas, o minerales, que sirven por sí solos a la Medicina, o entran a componer las drogas.

La mayoría de los simples procedían, en aquella época, del mundo vegetal, fuente principal de panaceas curativas ${ }^{21}$. La preparación de los medicamentos comenzaba en el mismo momento de la recolección de las plantas, que debían ser recogidas con el cielo raso y teniendo en cuenta el planeta que influía con sus emanaciones en cada una de las horas. En efecto, cada planeta influía sobre un determinado tipo o grupo de plantas, por lo que estas debían ser recogi-

17. J. R. Fraile, A. De Miguel y A. Yuste, «El dolor agudo en El Quijote», Revista Española de Anestesiología y Reanimación, 50, 2003, pp. 346-355.

18. M. Rey Bueno, Quijote mágico. Los mundos encantados de un hidalgo hechizado, Madrid, Algaba, 2005, pp. 80-82.

19. C. Solís y M. Sellés, Historia de la ciencia, Madrid, Espasa, 2005, p. 489.

20. Madrid, Real Academia Española, t. VI, 1739, pp. 116,2-117,1.

21. M. Rey BuENO, op. cit., pp. 74-77. 
das a una hora concreta para que poseyeran toda su virtud. Posteriormente, se separaban las partes de las plantas que tenían las virtudes medicinales: flores, frutas, hojas, etc. Para potenciar los efectos terapéuticos se podían juntar varios simples, dando lugar a un compuesto, según recetas conocidas desde la antigüedad, que se admitían sin más.

Recordemos a este respecto cómo el médico que debió sufrir Sancho en su gobierno quita de la vista un platonazo de olla podrida y nos pone en sobreaviso:

y la razón es porque siempre y a doquiera y de quienquiera son más estimadas las medicinas simples que las compuestas, porque en la simples no se puede errar, y en las compuestas sí, alterando la cantidad de las cosas de que son compuestas (I, 47, 1099).

En el caso del término «compuesto» leemos, ya en pleno siglo XVIII, que es un agregado de muchas cosas, que forman otra distinta, perfecta y cumplida ${ }^{22}$.

El Dioscórides del doctor Laguna, nombrado en la obra que nos ocupa (I, 18, 215), es la fuente bibliográfica principal de simples para los boticarios de la época y hasta el siglo XVIII. Era el Dioscórides la plasmación de la visión galénica del mundo natural, que quedaba dividido en tres grandes áreas: los vegetales, los animales y los minerales. Los primeros se consideran fundamentalmente medicamentos, como hemos visto; los segundos, alimentos; los últimos, venenos ${ }^{23}$.

No se observa en la obra ninguna influencia paracelsista en lo que se refiere al poder curador de los materiales inorgánicos ${ }^{24}$, como el propio Paracelso atribuyó al mercurio, el arsénico y el plomo. De hecho, cuando Sancho y don Quijote observan cómo se les acercan gran multitud de lumbres en la aventura de los encamisados,

... Sancho comenzó a temblar como un azogado... (I, 19, 218).

También, en el episodio en el que don Quijote da respuesta al eclesiástico, una vez que ha sido llamado «alma de cántaro» y ha escuchado poner en duda la existencia de gigantes en España, malandrines en la Mancha, ni Dulcineas encantadas, podemos leer cómo:

Levantado, pues, en pie don Quijote, temblando de los pies a la cabeza como azogado, con presurosa y turbada lengua dijo... (II, 32, 971).

Observemos cómo se dejan traslucir, con la ironía propia de la novela, las consecuencias neurotóxicas negativas de la ingestión o inhalación de mercurio, que se hacen visibles por la existencia de temblores, cambios emocionales — como vaivenes en el carácter_-, irritabilidad, nerviosismo, trastornos en las

22. RAE A 1729 (Madrid, Real Academia Española, t. II, 1729), p. 461,2.

23. J. Puerto, «La material medicinal de Dioscórides, Andrés Laguna y El Quijote», La ciencia y El Quijote, cit., p. 148.

24. M. Rey Bueno, «La botica alquimista», Azogue, n. ${ }^{\circ}$ 2, 1999 〈www.revistaazogue.com». 
sensaciones y cambios neuromusculares - como convulsiones nerviosas-. A exposiciones elevadas, se pueden tener efectos como insuficiencia renal o respiratoria y la muerte ${ }^{25}$.

La condesa Trifaldi comenta cómo mediante coplas y seguidillas se dejó embaucar por don Clavijo, haciendo posible la perdición de Antonomasia.

Allí era el brincar de las almas, el retozar de la risa, el desasosiego de los cuerpos y finalmente el azogue de todos los sentidos (II, 38, 1031).

Indica la Trifaldi, figuradamente, cómo se dejaba llevar hasta el trastorno en las sensaciones o la muerte de los sentidos.

Pero, a veces, la utilización de un metal como el mercurio no es tan negativa. En la embajada de Sancho, don Quijote se maravilla de la rápida vuelta de aquel, achacándolo todo a la ayuda de un sabio nigromante y encantador que tiene que ver con sus cosas y es su amigo. Sancho no duda en darle la razón:

-Así sería — dijo Sancho-, porque a buena fe que andaba Rocinante como si fuera asno de gitano con azogue en los oídos (I, 31, 396).

Se aplicaba el mercurio - el azogue - en las orejas de las caballerías como truco para darles ciertos bríos en momentos en los que la presencia de estos era necesaria ${ }^{26}$.

La ausencia de teorías paracelsistas, así como la utilización de los minerales como el mercurio en el sentido galénico de veneno, constituyen una prueba de la pobre difusión que las mismas tuvieron en la España del siglo XVI, dados los cuidados de la Iglesia frente a ideas exteriores. Efectivamente, el paracelsismo español poseyó un fuerte componente cortesano ${ }^{27}$; aunque hubo reconocidos seguidores de dichas teorías, como el médico valenciano Llorenc Cocar, que fue desde 1585 catedrático de cirugía en la misma Universidad valenciana donde se formó ${ }^{28}$.

\section{Alquimias ESOTÉRICA Y EXOTÉRICA}

En su origen, la alquimia era al mismo tiempo esotérica y exotérica, una mística sagrada expresada en términos materiales. A lo largo del tiempo ambas tendencias se irán alejando. La alquimia esotérica o religiosa tiene como fin la

25. Información de la Environmental Protection Agency de los Estados Unidos 〈www.epa.gov/mercury/effects.htm\#elem〉.

26. Don Quijote de la Mancha, ed. cit., p. 396, n. 26.

27. M. LóPEZ PÉrez y M. Rey Bueno, «La instrumentalizacion de la espagiria en el proceso de renovación: Las polémicas sobre los medicamentos químicos», Los hijos de Hermes. Alquimia y espagiria en la terapéutica española moderna, F. J. Puerto SARMiento (dir.), Corona Borealis, Madrid, 2001, p. 284.

28. J. Rodríguez Guerrero, «Censura y Paracelsismo durante el Reinado de Felipe II», Azogue, n. ${ }^{\circ}$ 4, 2001 〈www.revistaazogue.com». 
comprensión de la deidad y el objetivo de alcanzar la salvación, en términos cristianos. Es una mística que va abandonando los laboratorios y se va desarrollando como un fenómeno meramente espiritual. Como es sabido, este camino de perfección solo puede ser recorrido por algunos elegidos.

En este sentido podemos entender las palabras que don Quijote dirige al Caballero de Verde Gabán, refiriéndose a la poesía:

Ella es hecha de una alquimia de tal virtud, que quien la sabe tratar la volverá en oro purísimo de inestimable precio; hala de tener el que la tuviere a raya, no dejándola correr en torpes sátiras ni en desalmados sonetos... (II, 16, 826).

Se ha visto un uso metafórico de la imaginería alquímica en diversos lugares de la obra, incluso en el mismo sentido de la misma ${ }^{29}$.

Observemos a don Quijote describiendo un proceso muy parecido a lo que podría considerarse una redención alquímica, por ejemplo, en el episodio de las discretas altercaciones que don Quijote y el canónigo tuvieron:

... ¿hay mayor contento que ver, como si dijésemos, aquí ahora se muestra delante de nosotros un gran lago de pez hirviendo a borbollones, y que andan nadando y cruzando por él muchas serpientes, culebras y lagartos, y otros muchos géneros de animales feroces y espantables, y que del medio del lago sale una voz tristísima que dice: «Tú, caballero [...] si quieres alcanzar el bien que debajo destas negras aguas se encubre, muestra el valor de tu fuerte pecho y arrójate en mitad de su negro y encendido licor, porque si así no lo haces, no serás digno de ver las altas maravillas que en sí encierran y contienen los siete castillos de las siete fadas que debajo desta negrura yacen?» (I, 50, 623).

El episodio continúa describiendo cómo el caballero, sin considerar el peligro a que se expone, se arroja en mitad del bullente lago y termina por descubrir unos floridos campos, donde

... le parece que el cielo es más transparente y que el sol luce con claridad más nueva (I, 50, 623).

Del mismo cariz se presenta, ya en la segunda parte, el descenso de don Quijote a la cueva de Montesinos. Sancho, en su despedida, dice a su amo:

... ¡Dios te guíe, otra vez, y te vuelva libre, sano y sin cautela a la luz desta vida que dejas por enterrarte en esta escuridad que buscas! (II, 22, 890).

29. R. El SAFFAR, «Persiles' Retort: An Alchemical Angle on the Lovers' Labors», Cervantes: Bulletin of the Cervantes Society of America, 10, 1990, 1, pp. 18 y ss. 
En el capítulo siguiente, don Quijote cuenta su experiencia y rectifica las ideas de su escudero:

... de repente y sin procurarlo, me salteó un sueño profundísimo, y cuando menos lo pensaba, sin saber cómo ni cómo no, desperté dél y me hallé en la mitad del más bello, ameno y deleitoso prado que puede criar la naturaleza, ni imaginar la más discreta imaginación humana (II, 23, 893).

Ciertamente, en este episodio se ha pretendido ver la relación de un sueño ${ }^{30}$, un proceso de iniciación alquímica ${ }^{31} \mathrm{o}$, también, una bajada a los infiernos $^{32}$. Dilema este difícil de discernir y prueba evidente del conocido hecho de que cada uno de nosotros lee su propio Quijote. Quizá tampoco lo supiera claramente nuestro caballero andante, quien, en un momento de crisis comenta

Hasta agora no sé lo que conquisto a fuerza de mis trabajos (II, 58, 1198).

La alquimia exotérica tiene unos objetivos más prácticos, como son la obtención del oro terrenal o la inmortalidad. El oro y, en menor medida, la plata eran altamente estimados desde la antigüedad; ello contrasta con la pobre valoración de que eran objeto, también desde antiguo, los metales útiles: el hierro, el estaño, el cobre, el plomo y el mercurio ${ }^{33}$. Esta idea subyace en el discurso de la edad dorada de don Quijote:

-Dichosa edad y siglos dichosos aquellos a quien los antiguos pusieron nombre de dorados, y no porque en ellos el oro, que en nuestra edad de hierro tanto se estima, se alcanzase en aquella venturosa sin fatiga alguna, sino porque entonces los que en ella vivían ignoraban estas dos palabras de tuyo y mío (I, 11, 133).

Este discurso se repetirá más adelante:

- Sancho amigo, has de saber que yo nací por querer del cielo en esta nuestra edad de hierro para resucitar en ella la del oro, o la dorada, como suele llamarse (I, 20, 227).

Es llamativo el elevado número de veces que se cita al oro en comparación con el resto de los metales conocidos, que son nombrados en muy pocos mo-

30. A. Rosenblat, «La primera frase y los niveles lingüísticos del Quijote», Historia y critica de la literatura española, F. Rico (dir.), t. II: Siglos de oro: Renacimiento, Barcelona, Crítica, 1980, pp. 702-709.

31. M. Castillo Martos, El espíritu alquímico de don Quijote, Cuenca, Servicio de Publicaciones de la Universidad de Castilla-La Mancha, 2005, pp. 81-93.

32. M. ReY BuENO, op. cit., pp. 146-150.

33. J. SÁnchez Gómez, «La minería y la metalurgia en la España de El Quijote», La ciencia y El Quijote, cit., pp. 227-248. 
mentos. Ello se debe a la poco significativa presencia de los metales en la sociedad de tiempos de Cervantes. El bronce se utiliza como modelo de dureza en muy diversas ocasiones; en la mayoría de ellas aplicadas a la personalidad o al carácter, o a la eternidad de la fama de nuestro caballero.

En el primer sentido aparece en expresiones como:

... bien había de ser corazón de bronce el que con muestras de tanto dolor no se enterneciera (I, 36, 470).

En este mismo sentido también se utiliza el diamante o el risco.

En el segundo, en expresiones como:

Éste es, señor, el Caballero de la Triste Figura [...] cuyas valerosas hazañas y grandes hechos serán escritas en bronces duros y en eternos mármoles (I, 47, 596).

En ambos sentidos es también muy utilizado el mármol. Por el contrario, son la seda y el algodón utilizados en diversas ocasiones como ejemplos, figurados o no, de materiales blandos. Como vemos, ninguno de los materiales tratados es un metal.

El acero o el hierro acerado, son utilizados en mucha menor medida, y siempre en expresiones meramente descriptivas:

La lanza, que tenía arrimada a un árbol, era grandísima y gruesa, y de un hierro acerado de más de un palmo (II, 14, 808).

Pero existe un caso particularmente interesante de utilización de metales. Tiene lugar en el discurso de las armas y las letras:

... aunque a mí ningún peligro me pone miedo, todavía me pone recelo pensar si la pólvora y el estaño me han de quitar la ocasión de hacerme famoso... (I, 38, 491).

Se refiere el autor al peltre, una aleación de estaño, plomo y algún otro metal como cobre o cinc utilizada para fabricar balas. Ello es usado por el autor para mostrarnos el pesar y la inadaptación que sufre don Quijote ante los nuevos tiempos - tan lejanos de los de los caballeros andantes de otra época más dorada - en que uno puede ser alcanzado por «una desmandada bala» (ibíd.). Nuestro protagonista se siente indefenso ante un ataque furtivo de esta naturaleza, ya que va en contra de los más elementales principios de la caballería andante.

Dejando aparte las aplicaciones prácticas, a la alquimia exotérica se dedican los llamados sopladores, y sus lugares de trabajo se encuentran entre retortas, crisoles y alambiques. Pero los resultados de estos no se ven a corto plazo, lo que termina por desembocar en una falta de credibilidad que se ve acrecentada 
por la charlatanería y los timos por parte de algunos desaprensivos. Por ello, en la segunda parte, nuestro hidalgo hace notar a la sobrina la blasfemia en que incurre al censurar las historias de los caballeros andantes, aunque reconoce que

... no todos son corteses ni bien mirados: algunos hay follones y descomedidos; ni todos los que se llaman caballeros lo son de todo en todo, que unos son de oro, otros de alquimia, y todos parecen caballeros, pero no todos pueden estar al toque de la piedra de la verdad (II, 6, 735).

En realidad esa charlatanería tenía como objetivo la ganancia de dinero de una forma rápida y sin contemplaciones; en este sentido, cualquier vivo podía utilizar la alquimia o su parafernalia. En la aventura de los galeotes, aparece un personaje que ha sido alcahuete y aun hechicero. Don Quijote nos advierte a este respecto:

lo que suelen hacer algunas mujercillas simples y algunos embusteros bellacos es algunas misturas y venenos, con que vuelven locos a los hombres, dando a entender que tienen fuerza para hacer querer bien, siendo, como digo, cosa imposible forzar la voluntad (I, 22, 262-263).

Las prácticas descritas anteriormente mostraban un claro sentido opuesto a la purificación alquímica. El uso de conjuros, filtros y maleficios por hechiceros y alcahuetes se encontraba entre los actos más nombrados por las mujeres que fueron llamadas a la presencia del Santo Oficio. Rellenaban con diversos líquidos una serie de recipientes, a los que se conjuraba con diversas oraciones. Interpretaban el color del recipiente, el aspecto de la llama, o elaboraban bebedizos con los que subyugar la voluntad. Es este un determinismo rechazado por la Iglesia, lo que la lleva asimismo a someter a un espurgo sistemático las bibliotecas de brujos, adivinos, nigromantes y alquimistas; profesiones vistas por el Santo Oficio como malditas ${ }^{34}$. Don Quijote muestra su claro rechazo a las prácticas que no afirman la fortaleza de la voluntad y el libre albedrío, no considerándolas siquiera efectivas. De hecho, a veces, no hace falta ayuda alguna. Sancho nos recuerda en la historia de Camacho, Quiteria y Basilio:

... que el amor, según yo he oído decir, mira con unos antojos que hacen parecer oro al cobre, a la pobreza, riqueza, y a las lagañas, perlas (II, 19, 857).

De nuevo la alquimia rinde mérito a las palabras. 


\section{PROCESOS ALQUÍMICOS}

Los procesos alquímicos son puestos por el autor al servicio de la literatura, como no podía ser de otra manera. Entre estos procesos podemos nombrar ${ }^{35}$ :

- La calcinatio, calcinación, o tostación y fusión de un cuerpo al fuego; entendida por los alquimistas como una transformación de un metal en polvo, se trata en realidad de la formación de óxidos metálicos, o «cales metálicas», como fue llamada por los alquimistas.

El fuego también se utiliza en el arte de la metalurgia y en el ensayo de metales. En la novela de El curioso impertinente, escucha Lotario de Anselmo:

... el deseo que me fatiga es pensar si Camila, mi esposa, es tan buena y perfecta como yo pienso, y no puedo enterarme en esta verdad si no es probándola de manera que la prueba manifieste los quilates de su bondad, como el fuego muestra los del oro (I, 33, 415).

Posteriormente insiste Anselmo:

... deseo que Camila, mi esposa, pase por estas dificultades y se acrisole y quilate en el fuego de verse requerida y solicitada... (I, 33, 416).

- Putrefactio, putrefacción o corrupción, íntimamente relacionado con la mortificación o extinción de las partes impuras. Vendría a consistir en una trituración o destrucción del cuerpo.

- Sublimatio o sublimación. Consistente en una destilación en seco, un sólido es eliminado de la retorta por calentamiento; en el recipiente en el que es recogido vuelve de nuevo al estado sólido.

En el episodio de las tres aldeanas, Sancho y don Quijote se encuentran hincados de rodillas ante la princesa y señora universal del Toboso; esta pide a estos dos dispares hombres que se aparten del camino. Sancho aparenta dolerse:

... ¿Cómo vuestro magnánimo corazón no se enternece viendo arrodillado ante vuestra sublimada presencia a la coluna y sustento de la andante caballería? (II, 10, 771).

- Solutio o solución. Por este proceso, los alquimistas no entienden únicamente una disgregación de un sólido dentro del seno de un líquido, sino también, un proceso de licuación, un cambio de estado sólido a estado líquido.

Sancho dice a don Quijote, en el episodio sobre la embajada que aquel tuvo con la amada de nuestro caballero:

—Lo que sé decir — dijo Sancho- es que sentí un olorcillo algo hombruno, y debía de ser que ella, con el mucho ejercicio, estaba sudada y algo correosa $(I, 31,393)$.

35. F. J. Olivares del Valle, op. cit., pp. 87-90. 
Don Quijote se resiste a creerlo:

... yo sé bien a lo que huele aquella rosa entre espinas, aquel lirio del campo, aquel ámbar desleído (I, 31, 393).

En la aventura de los cueros de vino, Sancho no logra descubrir la cabeza del gigante, por lo que, una vez escuchadas las palabras del ventero, teme el incumplimiento de las promesas hechas por su amo:

... sólo sé que vendré a ser tan desdichado, que, por no hallar esta cabeza, se me ha de deshacer mi condado como la sal en el agua (I, 35, 456).

A veces, las mezclas no son homogéneas: en la segunda parte, hablan el bachiller Sansón Carrasco, Sancho y don Quijote sobre la conveniencia de intercalar la novela de El curioso impertinente por parte del autor en la primera parte:

-Yo apostaré — replicó Sancho- que ha mezclado el hideperro berzas con capachos (II, 3, 710).

Menos malsonante son estas otras palabras del narrador:

... la verdad adelgaza y no quiebra, y siempre anda sobre la mentira, como el aceite sobre el agua (II, 10, 763).

- Destillatio o destilación. Se deja evaporar en la retorta un líquido y luego se condensa por enfriamiento, por lo que cae de nuevo a la retorta gota a gota (solve et coagula). Ya vimos cómo el mercader pretendía la posibilidad de que la sin par Dulcinea manara bermellón y piedra azufre.

En el episodio de las discretas altercaciones que don Quijote y el canónigo tuvieron, cuenta nuestro hidalgo cómo tratan al caballero que se arroja al bullente lago lleno de pez y animales feroces, una vez superada la prueba de valor por arrojarse al mismo:

¿Qué es ver, pues, cuando nos cuentan que tras todo esto le llevan a otra sala [...]? ¿Qué el verle echar agua a manos, toda de ámbar y de olorosas flores distilada? (I, 50, 625).

En la preparación del combate con el Caballero del Bosque, podemos leer:

En esto, ya comenzaban a gorjear en los árboles mil suertes de pintados pajarillos, y [...] saludaban a la fresca aurora, que ya por las puertas y balcones del Oriente iba descubriendo la hermosura de su rostro, sacudiendo de sus cabellos un número infinito de líquidas perlas, en cuyo suave licor bañándose las yerbas, parecía asimismo que ellas brotaban y llovían blanco y menudo aljófar; los sauces destilaban maná sabroso, reíanse las fuentes...

(II, 14, 807). 
- Coagulatio, coagulación, solidificación o cristalización. Proceso de transformación de un cuerpo líquido en un sólido, o fijación.

- Extractio, o culminación de la obra por obtención de la tintura del cuerpo obtenido en el proceso anterior.

Otros procesos pueden ser:

- Digestio, fragmentar o digerir, sometiendo la materia sólida a la acción de un líquido a una cierta temperatura, con el fin de disolverla; también significa extraer, como por ejemplo, las esencias de las plantas.

Una suerte de digestio realiza uno de los cabreros aprovechando las virtudes tradicionales del romero y las propiedades cáusticas y antisépticas de la sal para curar la herida de la oreja que el vizcaíno cortó a nuestro hidalgo:

Y tomando algunas hojas de romero [...] las mascó y las mezcló con un poco de sal, y, aplicándoselas a la oreja, se la vendó muy bien, asegurándole que no había menester otra medicina, y así fue la verdad (I, 11, 139).

Por supuesto, la digestio más llamativa es la realizada para la obtención del bálsamo de Fierabrás (en I, 17), ya comentada.

- Ceratio, consistente en el ablandamiento de un sólido o el endurecimiento de un líquido, dando en cualquier caso, como resultado, una pasta.

En el episodio de la condesa Trifaldi, la dueña Dolorida dice de su aflicción que

... es tal, que es bastante a enternecer los mármoles y a ablandar los diamantes y a molificar los aceros de los más endurecidos corazones del mundo... (II, 38, 1027).

- Fermentatio o fermentación. Un proceso de este tipo se ve indirectamente involucrado en las palabras que Sancho intercambia con el escudero del Caballero del Bosque:
¿No será bueno, señor escudero, que tenga yo un instinto tan grande y natu- ral en esto de conocer vinos, que, en dándome a oler cualquiera, acierto la patria, el linaje, el sabor y la dura y las vueltas que ha de dar, con todas las circunstancias al vino atañederas? (II, 13, 799).

- Multiplicatio y projectio, procesos de difícil separación, consisten en la multiplicación cualitativa, o transformación de una materia de menos valor, como el plomo, en otra de mayor valor, como un metal noble. Pero también multiplicación cuantitativa, obteniéndose una mayor cantidad de oro. Refiriéndose Sancho a la venta de esclavos de su posible reino africano, juega con las dos variedades de la gran obra, la obra roja, que consiste en fabricar un metal noble como es el oro, y la obra blanca, que consiste en fabricar otro metal noble, la plata; en cualquier caso, todo consiste en el enriquecimiento:

... por negros que sean, los he de volver blancos o amarillos (I, 29, 373). 


\section{ATOMISMO}

En el último tercio del siglo XV se imprimieron el De rerum natura del atomista Lucrecio y las Vidas de los filósofos más ilustres de Diógenes Laercio. Además se realizaron las traducciones de Marsilio Ficino del Corpus hermeticum, de los diálogos de Platón y de las obras de Plotino y otros neoplatónicos. El conocimiento de estos textos, entre otros, propiciaron la existencia de una visión diferente a la del mundo aristotélico. La física de Aristóteles comenzó a ser considerada como una física entre otras ${ }^{36}$. En el siglo XVI, algunos aristotélicos heterodoxos intentaron desarrollar una filosofía de la ciencia natural, pero las filosofías de corte neoplatónico tomaron cierto vuelo asociadas a la astronomía copernicana, los nuevos conocimientos del cielo y la idea de que la naturaleza posee una estructura matemática; sin embargo, a mediados del siglo XVII se verían desplazadas por la filosofía de naturaleza atomista $^{37}$.

En nuestra famosa obra aparecen siete referencias al átomo. Todas ellas en la segunda parte, de 1615. La primera, en el mismo capítulo primero, en el que el cura y el barbero trataron con don Quijote acerca de su enfermedad.

—En esto de gigantes — respondió don Quijote - hay diferentes opiniones, si los ha habido o no en el mundo, pero la Santa Escritura, que no puede faltar un átomo en la verdad, nos muestra que los hubo, contándonos la historia de aquel filisteazo de Golías... (II, 1, 693-694).

En el Diccionario de Autoridades de 1726 se nos dice que un átomo es el cuerpo más pequeño que se puede considerar, por lo que es incapaz de dividir$\mathrm{se}^{38}$. Por otra parte, se nos aclara que «no exceder en un átomo» es «decir o hacer alguna cosa sin añadirle, ni quitarle nada», con lo que toma pleno sentido la utilización literaria del concepto de átomo que lleva a cabo el autor de la obra.

El último momento en el que el autor hace uso de la palabra átomo tiene lugar en el capítulo en que todo culmina, en el que nos cuesta decidir si la tristeza que nos embarga se debe a la presencia de la muerte o a la ausencia de la locura.

Don Quijote [...] en aquel mismo punto se apartó a solas con el bachiller y el cura, y en breves razones les contó su vencimiento y la obligación en que había quedado de no salir de su aldea en un año, la cual pensaba guardar al pie de la letra, sin traspasarla en un átomo... (II, 73, 1325).

36. M. Cortés Arrese, «El Renacimiento», Cuadernos Historia 16, n. ${ }^{\circ}$ 24, Madrid, Historia 16, 1995, p. 162.

37. C. Solís y M. SEllés, op. cit., p. 310.

38. RAE A 1726 (Madrid, Real Academia Española, t. I, 1726), p. 471,2. 
Debe hacerse notar que la palabra átomo se pone en boca de un melancólico. Alguien a quien se le secó el cerebro de tanta lectura, llegando a perder el juicio.

Recordemos que en el capítulo III de la segunda parte asistimos a un graciosísimo coloquio en el que tiene lugar el ridículo razonamiento que pasó entre don Quijote, Sancho y el bachiller. Los adjetivos señalados son utilizados por el propio autor, siendo el gran socarrón del bachiller el que utiliza el término átomo. El pequeño Sansón Carrasco, entre bromas y veras, se atreve a decir las valientes palabras siguientes:

... pero quisiera yo que los tales censuradores fueran más misericordiosos y menos escrupulosos, sin atenerse a los átomos del sol clarísimo de la obra de que murmuran... (II, 3, 713).

La sorpresa de un lector actual es mayúscula al leer estas palabras, sin embargo, si recurrimos al citado Diccionario de Autoridades de 1726, comprobamos qué idea intuitiva de átomo se maneja en una época relativamente cercana a la que se escriben estas palabras. De hecho, «átomos, se suelen llamar por su pequeñez las pequeñas moticas que andan por el aire tan imperceptibles que solo las vemos al rayo del Sol cuando entra por los resquicios de las ventanas ${ }^{39}$.

La cuarta vez que se utiliza el vocablo se hace por boca del titiritero, en el episodio del retablo de Melisendra:

Prosigue, muchacho, y deja decir, que como yo llene mi talego, siquiera represente más impropiedades que tiene átomos el sol (II, 26, 928).

El maese Pedro no era otro que Ginés de Pasamonte, tal como se nos desvela en II, 27. Perseguido por la justicia, había huido al reino de Aragón, haciéndose pasar por tuerto (signo de bellaquería) y acomodándose al oficio de titerero, ya que sabía de este oficio como del de jugar de manos. Pone Cervantes en boca de este bellaco personaje una versión alterada de la ya comentada frase hecha de los átomos del sol dentro de la intención general de que el lector muestre menosprecio o desagrado hacia el propio personaje; de hecho, se ha identificado a este con Jerónimo de Pasamonte, y a este último con Avellaneda ${ }^{40}$. Sean tres, o uno, ninguno recibía, precisamente, las mejores loas de Cervantes.

También aparece el término en el capítulo X, capítulo que el autor de la historia preferiría no contar ya que

... las locuras de don Quijote llegaron aquí al término y raya de las mayores que pueden imaginarse, y aun pasaron dos tiros de ballesta más allá de las mayores. Finalmente, aunque con este miedo y recelo, las escribió de la

39. Ibíd.

40. H. Percas de Ponseti, «Un misterio dilucidado: Pasamonte fue Avellaneda», Cervantes: Bulletin of the Cervantes Society of America, 22, 2002, 1, pp. 127-154. 
misma manera que él las hizo, sin añadir ni quitar a la historia un átomo de la verdad... (II, 10, 763).

De nuevo, en el episodio de Clavileño, se piden muestras de agradecimiento a Cide Hamete - el verdadero autor de la obra-, puesto que

Pinta los pensamientos, descubre las imaginaciones, responde a las tácitas, aclara las dudas, resuelve los argumentos; finalmente, los átomos del más curioso deseo manifiesta (II, 40, 1037).

Podemos observar el uso del término como parangón de lo ínfimo.

Otra ocasión tiene lugar al insistirse de nuevo en el crédito que merece el celebérrimo autor:

Dice Cide Hamete, puntualísimo escudriñador de los átomos desta verdadera historia, que... (II, 50, 1130).

Se puede establecer una relación entre el tratamiento de la palabra átomo dentro del texto y la evolución del personaje, autor de esa verdadera historia.

Ya hemos comentado que la palabra átomo no aparece en la primera parte. También es de notar que el personaje de Cide aparece como autor ficticio, en la primera parte, a partir del capítulo IX. Reparemos en que el autor «era moro [...], y de los moros no se podía esperar verdad alguna, porque todos son embelecadores, falsarios y quimeristas» (II, 3, 704). De manera que desde la primera parte Cervantes deposita irónicamente la responsabilidad de lo narrado en un no creyente ${ }^{41}$.

Sin embargo, es en la segunda parte donde el autor toma mayor importancia como recurso retórico, creciendo, asimismo el tratamiento del mismo con una intención burlesca. Cide Hamete llega a no comprender los caracteres de los personajes y a malinterpretar los hechos ${ }^{42}$. Aparece en aquellos episodios más discutiblemente verosímiles o en los momentos más cómicos y risibles de la historia de don Quijote ${ }^{43}$. Se convierte en el personaje cómico más consistente de la segunda parte de la novela, llegando a sustituir, o al menos a rivalizar, con don Quijote como objeto de risa ${ }^{44}$.

Es en esta fase en el desarrollo del personaje en el que el término átomo se utiliza tres veces en relación con él. Siempre dando cuenta irónica y jocosamente del carácter fidedigno de lo que cuenta en relación con la historia.

41. C. Segre, «Líneas estructurales del Quijote», Historia y crítica de la literatura española, F. Rico (dir.), t. II, cit., p. 680.

42. H. Mancing, "Cervantes as Narrator of Don Quijote», Cervantes: Bulletin of the Cervantes Society of America, 23, 2003, 1, pp. 117-140.

43. J. G. Maestro, «El sistema narrativo del Quijote: la construcción del personaje Cide Hamete Benengeli», Cervantes: Bulletin of the Cervantes Society of America, 15, 1995, 1, pp. 111-141.

44. H. Mancing, «Cide Hamete Benengeli vs. Miguel de Cervantes. The metafictional dialectic of Don Quijote», Cervantes: Bulletin of the Cervantes Society of America, 1, 1981, 1-2, pp. 63-81. 
Recapitulemos: El término átomo es puesto por Cervantes en relación con un melancólico que ha perdido el juicio, con un bachiller socarrón, con un bellaco perseguido por la justicia y con un historiador del que hemos perdido toda confianza. Estos hechos, unidos, nos permiten hacernos una idea del estatus del atomismo en la España de finales del siglo XVI y principios del XVII. Es evidente su descrédito.

El modelo atomista estaba, desde su origen democríteo, basado en la necesidad. Ello sirvió a Epicuro para combatir la superstición religiosa y liberar a las personas del miedo a la acción divina. Los detractores cristianos del epicureísmo no soportaron el determinismo que provoca el cambio según necesidad, ni la negación de una autoridad suprema dictadora de conductas que premiase o castigase a los hombres. Por ello, el atomismo quedó eclipsado durante la Edad Media por las ideas aristotélicas, mucho más adaptables a la forma cristiana de búsqueda del fin último. En la Edad Media el epicureísmo se conoce, así, de manera imprecisa y con peyorativas y vagas connotaciones de ateísmo, materialismo o afición a los placeres terrenales, que lo lastran durante siglos ${ }^{45}$. Aunque durante el Renacimiento el redescubrimiento de los textos de Lucrecio y Diógenes Laercio significaron una nueva etapa de tenue aprecio por el epicureísmo, no parece, a tenor del uso que se da en nuestra famosa novela, que alcanzara a los lectores de la misma en la época en la que fue escrita.

\section{CONCLUSIONES}

Los conocimientos científicos de Cervantes son los habituales entre las personas instruidas de finales del siglo XVI y principios del XVII. En una época en la que los lenguajes de la ciencia y de las humanidades siguen siendo los mismos, el autor recoge los tópicos de aquella y los modifica, o juega con ellos, para obtener un efecto expresivo o humorístico. Muchos de esos tópicos están emparentados con las corrientes herméticas, mágicas o supersticiosas de origen altomedieval. Ello no es de extrañar; de hecho, también en el Dioscórides del doctor Laguna podemos encontrar tendencias de este tipo.

Debemos partir de la base de que la novela no es más que una invectiva contra los libros de caballerías; sin embargo, Cervantes utiliza en la obra las ideas alquímicas en la mayoría de sus diversas y complejas manifestaciones.

Hace a don Quijote el arquetipo de tipo neoplatónico del caballero andante. Sin embargo, evita los aspectos herméticos más comprometidos, como la existencia de una vida cósmica, que estarían en abierta contradicción con las ideas religiosas imperantes.

45. C. García Gual, Epicuro, Madrid, Alianza, 1981, p. 252. 
Utiliza, asimismo, la idea aristotélica de los elementos y sus proporciones, que abren la posibilidad de la transmutación de sustancias de bajo valor en el buscado oro. Dichos elementos y sus proporciones están en consonancia con una tradición clásica que también es aplicable al ser humano en un sentido galénico. Ello se enmarca dentro del ambiente científico de la época, que aún baraja como posible la influencia astrológica sobre el ser humano y el paralelismo entre el macrocosmos y el microcosmos.

Cervantes utiliza el tópico de origen árabe por el que se atribuyen virtudes terapéuticas a la piedra filosofal: como tintura para la transmutación es una medicina para los metales (el yelmo de Mambrino); como elixir para la inmortalidad, una medicina para el ser humano (el bálsamo de Fierabrás).

Ahora bien, la piedra filosofal se identifica con el conocimiento de Dios, quien puede ayudar en el camino de perfección del hombre y de la naturaleza. Tópico este, utilizado por Cervantes cuando don Quijote reza sobre la alcuza en la que fabrica el famoso bálsamo.

El autor incorpora también visiones populares de la alquimia en relación con los ámbitos boticarios de aplicación de esta: aguas de virtud, medicinas simples y compuestas, etc., sin que se puedan encontrar rastros de paracelsismo.

Asimismo, utiliza las visiones costumbristas de las alquimias exotérica y esotérica. Con respecto a la primera, el autor conoce los procesos alquimistas más comunes (digestión, sublimación...). En lo que se refiere a la segunda, el autor usa el carácter simbólico y alegórico del viaje hacia la perfección propio del alquimista (Cueva de Montesinos, por ejemplo). Sin embargo, no todo camino a la perfección debe considerarse un camino alquímico, por lo que debemos aceptar como igualmente posibles otras interpretaciones diferentes a las puramente alquimistas. Ello no es en ningún caso una limitación; todo lo contrario, nos permite leer la obra con la libertad propia de la «obra perfecta».

Una lectura comparativa entre los aspectos científicos y humanísticos permite entresacar qué grado de aceptación tienen algunas ideas entre las gentes educadas de la época de publicación de la obra. Ello ha sido útil a la hora de analizar el papel del atomismo. Es de destacar el descrédito del mismo, lo que se refleja en el uso que el autor hace de este a través de los personajes de la novela.

Sería interesante continuar con un estudio comparativo y simbiótico entre ambos ámbitos del conocimiento (científico y humanístico) a través de otras obras del autor. Ello nos permitiría profundizar en el conocimiento de los personajes y se tendría una visión más amplia de las obras de este. Sería también interesante ampliar este tipo de estudios a las obras de otros autores. 


\title{
Resumen
}

En la época de publicación del Quijote aún no se han escindido los lenguajes humanista y científico. En el presente trabajo se han indagado pasajes de la novela que hacen posible relacionar ambos ámbitos del conocimiento. Ello permite entender las ideas que una persona culta de la época posee sobre lo que, en un sentido amplio, conocemos como ciencia. Además, ciertas ideas científicas se utilizan de manera creativa desde el punto de vista literario. Entender dichas ideas conlleva el conocer con mayor riqueza aspectos puramente artísticos de la obra. Esa relación simbiótica se circunscribe en este trabajo al ámbito alquímico en sus diversas manifestaciones. También es posible encontrar rastros de atomismo.

Palabras clave: Quijote. Sancho. Ciencia. Alquimia. Atomismo.

Title: Alchemy and atomism in the Quixote

\begin{abstract}
When the Quixote was published, the scientific and humanist languages were not split yet. In this work, passages in the novel have been studied that enable to relate both fields of knowledge. This allows us to understand the ideas that an educated person of that time had on what, in a wide sense, we know as science. Moreover, some scientific ideas are used in a creative way from a literary point of view. Understanding these ideas involves knowing more extensively purely artistic aspects of the novel. That symbiotic relation is limited in this work to the alchemical area in its diverse manifestations. It is also possible to find traces of atomism.
\end{abstract}

Key words: Quixote. Sancho. Science. Alchemy. Atomism. 